\title{
The Flot2 component of the lipid raft changes localization during neural differentiation of $\mathrm{P} 19 \mathrm{C} 6$ cells
}

\author{
Kei Hanafusa and Nobuhiro Hayashi* ${ }^{*}$
}

\begin{abstract}
Background: Flotillin-2 (Flot2) is a lipid raft scaffold protein that is thought to be related to neural differentiation. Flot2 is phosphorylated by Fyn, a Src kinase, and causes raft-dependent endocytosis; however, the exact role of Flot2 in neural differentiation remains unclear. To reveal the roles of lipid raft-associated proteins during neural differentiation, we tried to analyze the expression and localization.

Results: In this study, we found that the expression levels of the Flot2 and Fyn proteins increased in whole-cell lysates of P19C6 cells after neural differentiation. In addition, sucrose density fractionation and immunofluorescence experiments revealed an increase in the localization of Flot2 and Fyn to lipid rafts after neural differentiation. We also found that Fyn partially colocalized with Flot2 lipid rafts in neural cells.

Conclusion: The observed distribution of Fyn and level of inactivated Fyn and/or c-Src in detergent-resistant membrane (DRM) fractions suggests that the amount of activated Fyn might increase in DRM fractions after neural differentiation. Overall these findings suggest that Flot2 lipid rafts are associated with Fyn, and that Fyn phosphorylates Flot2 during neural differentiation of P19C6 cells.
\end{abstract}

Keywords: Lipid raft, Neural differentiation, Flot2, Fyn, C-Src, P19C6 cells

\section{Background}

Neural differentiation is a remarkable phenomenon that contributes to the formation and function of the central nervous system. The differentiation process makes use of lipid rafts, which are microdomains present on the plasma membrane that contribute to signal transduction, cell-cell adhesion, neurite elongation, and the function of receptors for neurotrophic factors [1-7]. Therefore, analyses of lipid rafts are expected to yield important information for understanding the development and function of the central nervous system.

Lipid rafts are formed in specific regions that are abundant in glycosphingolipids and cholesterol; these regions can be isolated by sucrose density fractionation as a low buoyant density fraction [8-10]. Lipid rafts promote intracellular signaling by associating with acylated proteins [7, 11-13].

\footnotetext{
* Correspondence: nhayashi@bio.titech.ac.jp

School of Life Science and Technology, Tokyo Institute of Technology,

Meguro-ku, Tokyo, Japan
}

The flotillin protein family contains two members, flotillin-1 (Flot1) and flotillin-2 (Flot2), which are expressed constitutively in cells, highly homologous, and conserved from bacteria to mammals [7, 14-16]. Flots were initially identified as gene products that were upregulated in optic nerve lesions and during axon regeneration in goldfish [17]. Subsequently, Flots were found to be essential for neurite elongation, and Flot2 knockout mice exhibit impaired neuron maturation [18], hence, Flot2 is thought to play a role in neural differentiation.

Flot1 and Flot2 are localized to lipid raft regions via palmitoylation (Flot1 and Flot2) and myristoylation (Flot2). These proteins act as scaffolds for lipid rafts by forming homo- and hetero-oligomers [19, 20]. Flots reportedly interact with cytoskeletal proteins such as tubulin and actin via their stomatin/Prohibitin/Flotillin/HflK/C (SPFH) domains [21, 22]. In particular, tyrosine phosphorylation of Flots by the Src kinases results in the migration of Flots from the vicinity of the cell membrane to the cytosol [23, 24]. Flot2 interacts with $N$-methyl-D-aspartate receptors and interacts with Rab11a-expressing vesicles to promote 
endocytic transport of postsynaptic density-95, N-cadherin, and glutamate receptors $[19,25,26]$.

The tyrosine kinases pp59 ${ }^{\mathrm{Fyn}}$ (Fyn) and pp60-Src $(\mathrm{c}-\mathrm{Src})$ are lipid raft markers [23] that serve as signal transduction factors for cytoskeletal regulation [22, 27]. Fyn is related to neuronal differentiation [28] and neurite outgrowth is inhibited in fyn-minus mice [29]. Fyn and c-Src are localized in lipid rafts as a result of myristoylation and palmytoylation. $\mathrm{Ca}^{2+}$-bound calmodulin interacts with myristoylated Fyn and c-Src and regulates their localization [30, 31]. Cterminal Src kinase regulates the phosphorylation of Fyn at Y528 and c-Src at Y530, and these phosphorylated forms are inactive [32, 33]. The inactive forms of Fyn (pY528) and c-Src (pY530) are activated by dephosphorylation [34]. Notably, Fyn and c-Src are bound to membrane-bound $\gamma$-tubulin via their $\mathrm{SH} 2$ domain and the resulting complexes have been implicated in neural differentiation [35].

Neural differentiation can be modeled using P19C6 cells, which are subclones of a multipotent embryonic carcinoma cell line P19. Stimulation of P19 cells with high concentrations of retinoic acid results in the formation of embryonic bodies and induces neural differentiation. To our knowledge, studies of lipid rafts in P19 cells have not been performed to date. Moreover, P19 would not express Flot1, and the expression of Flot2 in this cell line has been reported [16]. Therefore, in the present study, we examined the functions of lipid rafts during neural differentiation in the P19C6 cell line by examining the localizations of Flot2, Fyn, and c-Src as lipid raft components.

\section{Results}

Flot2 expression during neural differentiation of P19C6 cells

The expression level of the mRNA encoding Flot2 changes during neural differentiation of human multipotent stromal cells (hMSCs) [36]. To determine whether the expression level of the Flot2 protein also changes during neural differentiation, we used western blotting (WB) to compare Flot2 protein levels in undifferentiated P19C6 cells with those undergoing neural differentiation (Fig. 1a). The level of Flot2 in whole-cell lysates was increased with neural differentiation (Fig. 1b). Octamer transcription factor-3 (Oct-3), a stem cell marker protein [37], was detected only on Day 0 (prior to neural induction) (Fig. 1b). On the other hand, the expression level of the neural marker microtubule-associated protein 2 (MAP2) [38] increased from Day 4 to Day 8 of neural induction (Fig. 1b). The expression level of Flot2 increased gradually during neural differentiation and was 1.6-fold higher on Day 8 than on Day 0 ( $p<0.05$; Fig. 1c). Fluorescent microscopy confirmed the presence of morphological changes typical of neural differentiation, including elongated neurites extending from the soma, in the induced cells (Additional file 2: Figure S2).
Next, the levels of Fyn and c-Src, and the combined level of phosphorylated Fyn (pY528) and/or phosphorylated c-Src (pY530), were assessed by WB [39-41]. The expression level of Fyn was 2.3-fold higher on Days 7 and 8 than on Day $0(p<0.05$; Fig. 1d). By contrast, cSrc expression did not change during neural differentiation (Fig. 1e). The combined level of Fyn (pY528) and/ or c-Src (pY530) increased gradually during neural differentiation and was 2.7-fold higher on Day 8 than on Day $0(p<0.05$; Fig. $1 \mathrm{f})$.

$\mathrm{Na} / \mathrm{K}$ ATPase (NKA) is a non-raft and plasma membrane marker that interacts with $\mathrm{c}$-Src and protein kinase $C[42,43]$. We used WB to examine the expression levels of the $\alpha 1$ subunit of NKA in differentiated and undifferentiated P19C6 cells. The expression level of NKA on Day 8 was 2.6 -fold higher than that on Day $0(p<$ 0.05 ; Fig. 1g). This observation is consistent with a previous study showing that NKA expression was 2.64-fold higher on Day 8 than on Day 0 of P19 cell neural differentiation [44].

Based on the results described above, we defined Day 0 as undifferentiated cells (UD) and Day 8 as neural differentiated cells $(\mathrm{Neu})$.

\section{Localization of lipid raft markers and a non-raft marker during neural differentiation of $\mathrm{P} 19 \mathrm{C} 6$ cells}

Next, we performed WB analyses of sucrose density fractions to examine the distributions of lipid raft markers (Flot2, Fyn, c-Src, Fyn (pY528) and/or c-Src (pY530)) and a non-raft marker (NKA) before and after neural differentiation of P19C6 cells (Fig. 2a-e). It is known that lipid rafts are present in detergent-resistant membrane (DRM) fractions (Frs) that appear at the interface between sucrose concentrations of 30 and 5\%. The levels of fractionated proteins that are associated with lipid rafts are decreased by methyl- $\beta$-cyclodextrin $(\mathrm{M} \beta C D)$ treatment, which depletes cholesterol from plasma membrane [45]. M $\beta C D$ treatment of P19C6 cells reduced the intensities of the bands representing Flot2, Fyn, c-Src, and Fyn (pY528) and/or c-Src (pY530) in Frs 4, 5, and 6 (Fig. 2a-d). NKA was detected in Frs 9 to 12 but not Frs 4, 5, and 6 (Fig. 2e). Therefore, we defined Frs 4, 5, and 6 as DRM Frs, and the other Frs as nonDRM Frs. As shown in Fig. 2a and f, DRM-associated Flot2 was increased after neural differentiation.

In whole-cell lysates, the level of Fyn and the combined level of phosphorylated Fyn (pY528) and/or phosphorylated c-Src (pY530) increased during neural differentiation (Fig. 1d and f). Figure 2 shows the distributions of Fyn, cSrc, and phosphorylated Fyn (pY528) and/or phosphorylated c-Src (pY530) in sucrose density Frs and their recovery ratios in DRM Frs. The recovery ratio of Fyn in DRM Frs did not change during neural differentiation (Fig. 2g). The recovery ratio of phosphorylated Fyn (pY528) and/or 


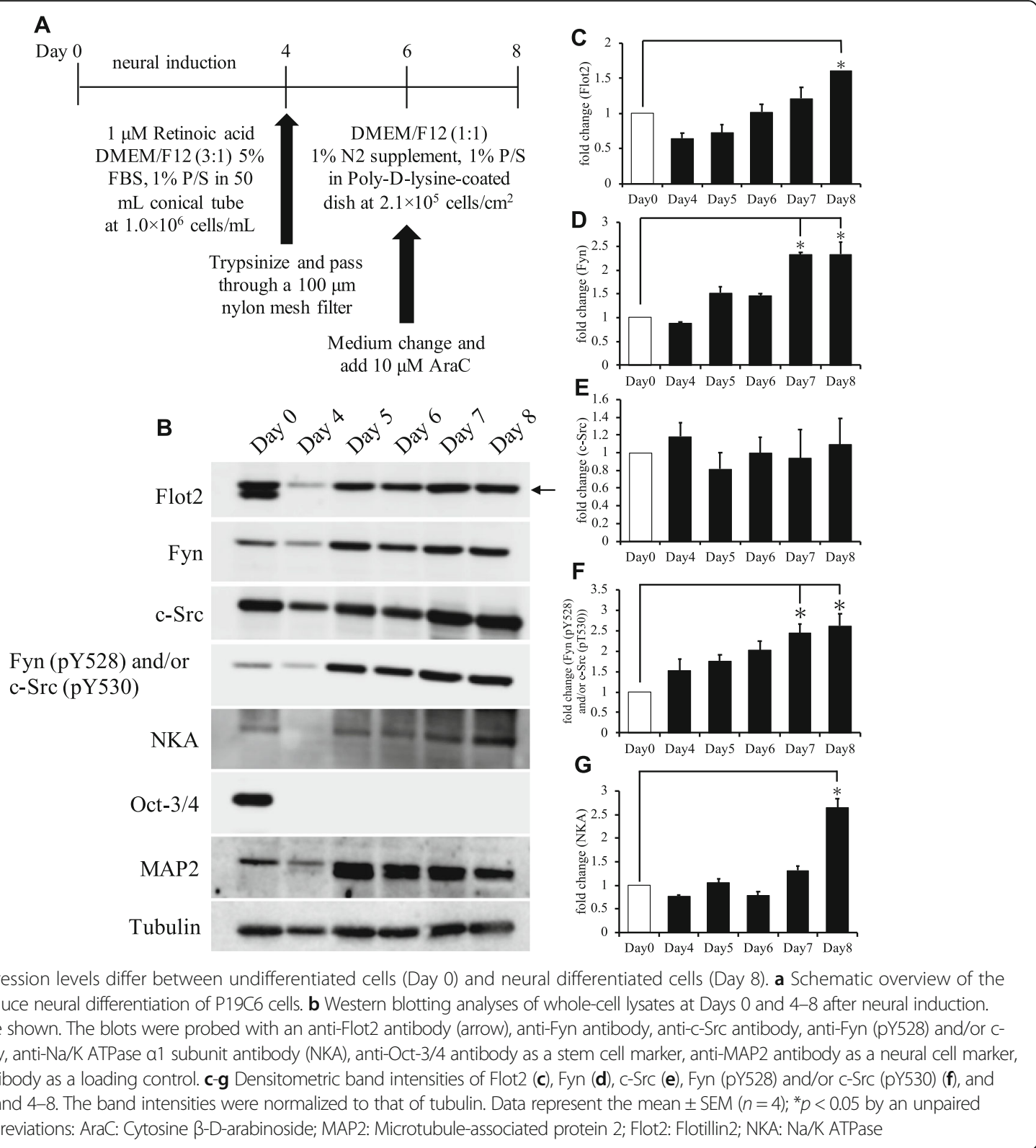

phosphorylated c-Src (pY530) in DRM Frs was decreased in Neu, while that in non-DRM Frs was increased (Fig. 2i). By contrast, the level of c-Src did not change during neural differentiation (Fig. 1e), and the recovery ratio of c$\mathrm{Src}$ in DRM Frs was decreased in Neu (Fig. 1h).

Because Flot2 in DRM Frs was increased after neural differentiation, we examined the localization of Flot2 to lipid rafts in UD and Neu P19C6 cells. The cells were costained with an anti-Flot2 antibody and Cholera toxin subunit $B(\mathrm{CTB})$, a non-toxic component of cholera holotoxin (Additional file 1: Figure S1A and Additional file 2: Figure S2A). CTB can bind to GM1, a glycosphingolipid containing sialic acid, and forms lipid rafts by its physiochemical property. Flot2 is localized in GM1-containing lipid rafts in T cells [46]. In UD cells, Flot2 seemed to be located proximal to the plasma membrane. Following neural differentiation, Flot 2 was located in the neurites and soma (Additional file 2: Figure S2A). In Neu cells, it seems that Flot2 and CTB colocalized signals, which were not colocalized with NKA, were in neurite (Additional file 2: Figure S2A and D).

Next, we compared the localization of Flot2 with that of the lipid raft markers Fyn and $\mathrm{c}-\mathrm{Src}$ in UD and Neu cells. In both cell types, Fyn showed a spotty distribution whereas c-Src was localized along the cell membrane (Fig. 3, Additional file 1: Figure S1, and Additional file 2: Figure S2). Fyn and c-Src may partially colocalize with Flot2 in UD cells. By contrast, 


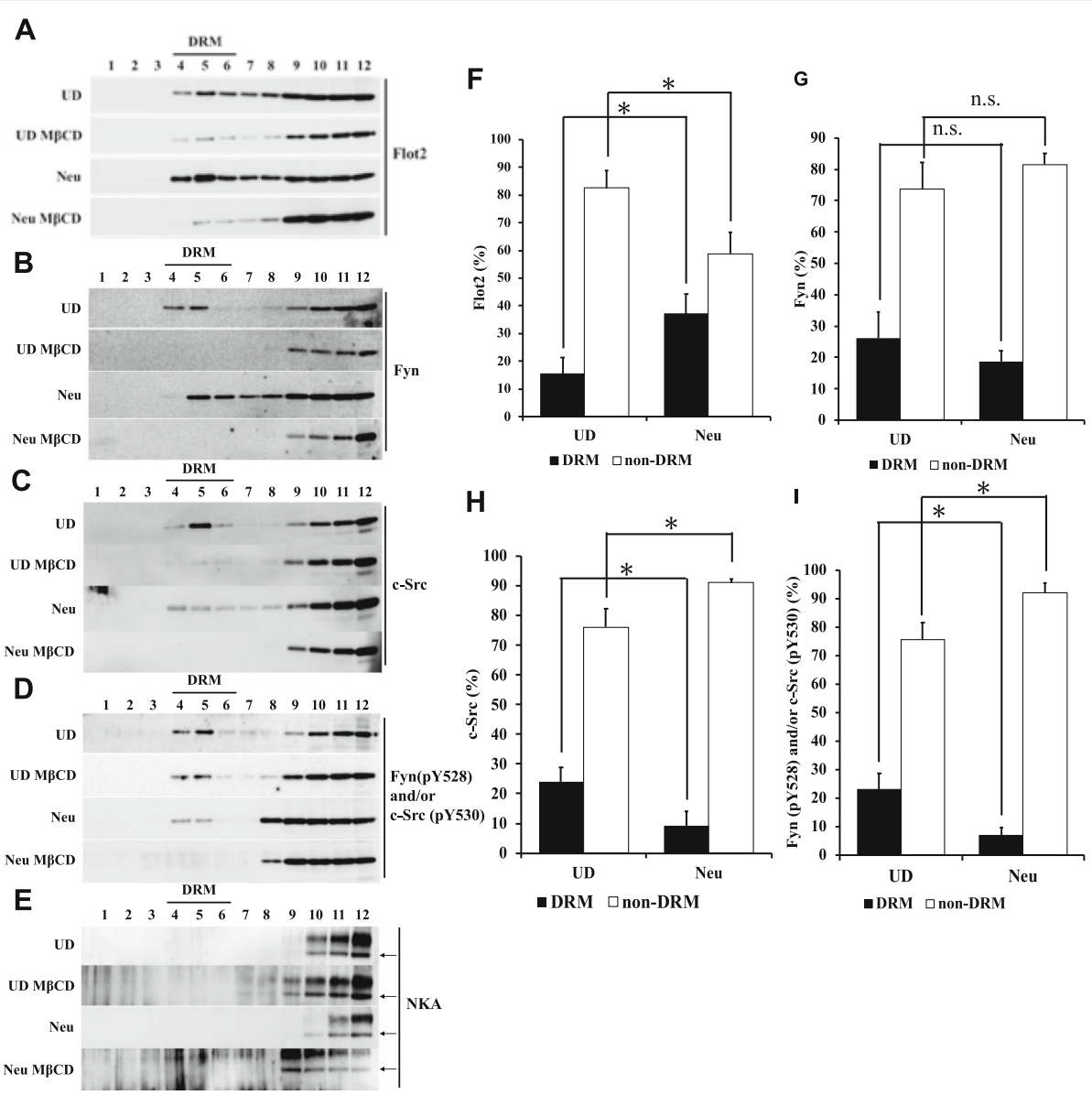

Fig. 2 Western blotting analyses of sucrose density fractions. a-e Representative results of western blotting analyses of sucrose density fractions of undifferentiated (UD) and neural differentiated (Neu) P19C6 cells, treated with or without MBCD. The fractions were incubated with antibodies against Flot2 (a), Fyn (b), c-Src (c), Fyn (pY528) and/or c-Src (pY530) (d), and NKA (e). Cropped images are shown. f-i Densitometric intensity analyses of the bands shown in a-d, representing the relative levels of Flot2 (f), Fyn (g), c-Src (h), and Fyn (pY528) and/or c-Src (pY530) (I) in the DRM (Frs. 4-6) and non-DRM fractions (Frs. 7-12) of UD and Neu cells. Data are represented as the mean \pm SEM $(n=6) ;{ }^{*} p<0.05$ by a two-tailed unpaired Student's t-test. Abbreviations: Flot2: Flotillin2; NKA: Na/K ATPase; DRM: Detergent-resistant membrane; M $\beta C D$ : methyl- $\beta$-cyclodextrin

Fyn may partially colocalize with CTB or Flot2 in neurites (Fig. 3c).

\section{Discussion}

To our knowledge, the work presented here is the first lipid raft analysis of P19C6 cells before and after neural differentiation. P19C6 embryonic carcinoma cells are widely used as a neuronal differentiation model. Notably, P19 cells are thought to be more sensitive to chemicals than other in vitro neuronal models, including rat adrenal pheochromocytoma PC12 cells and human neuroblastoma SH-SY5Y cells [47]. Based on this characteristic, we hypothesized that P19 cells could serve as a model for lipid raft analysis of neuronal differentiation induced by retinoic acid.

In P19C6 cells, the Flot2 protein level in whole-cell lysates and DRM Frs and the recovery ratio of Flot2 in DRM Frs were significantly higher than in non-DRM Frs after neural differentiation. In a previous study, neural differentiation of hMSCs induced upregulation of the Flot 2 mRNA level and relocalization of the Flot2 protein to the plasma membrane and lipid raft Frs [36] . However, in PC12 cells, which are frequently used as models of nerve-like cells, Flot1, but not Flot2, is upregulated after neural differentiation [48]. P19 cells and hMSCs are multipotent cells that are able to differentiate into multiple cell types, whereas PC12 cells are derived from the adrenal gland and yield only neuron-like cells upon differentiation [36, 49, 50]. Moreover, P19 and PC12 cells exhibit specific differences in differentiation. Notably, P19 cells resemble the original cells that they were derived from in the embryo, and can differentiate into neural cells by forming embryoid bodies upon retinoic acid stimulation [51].

NKA is a multi-subunit protein [52]. The $\alpha 1$ subunit of NKA is a non-raft and plasma membrane marker that 


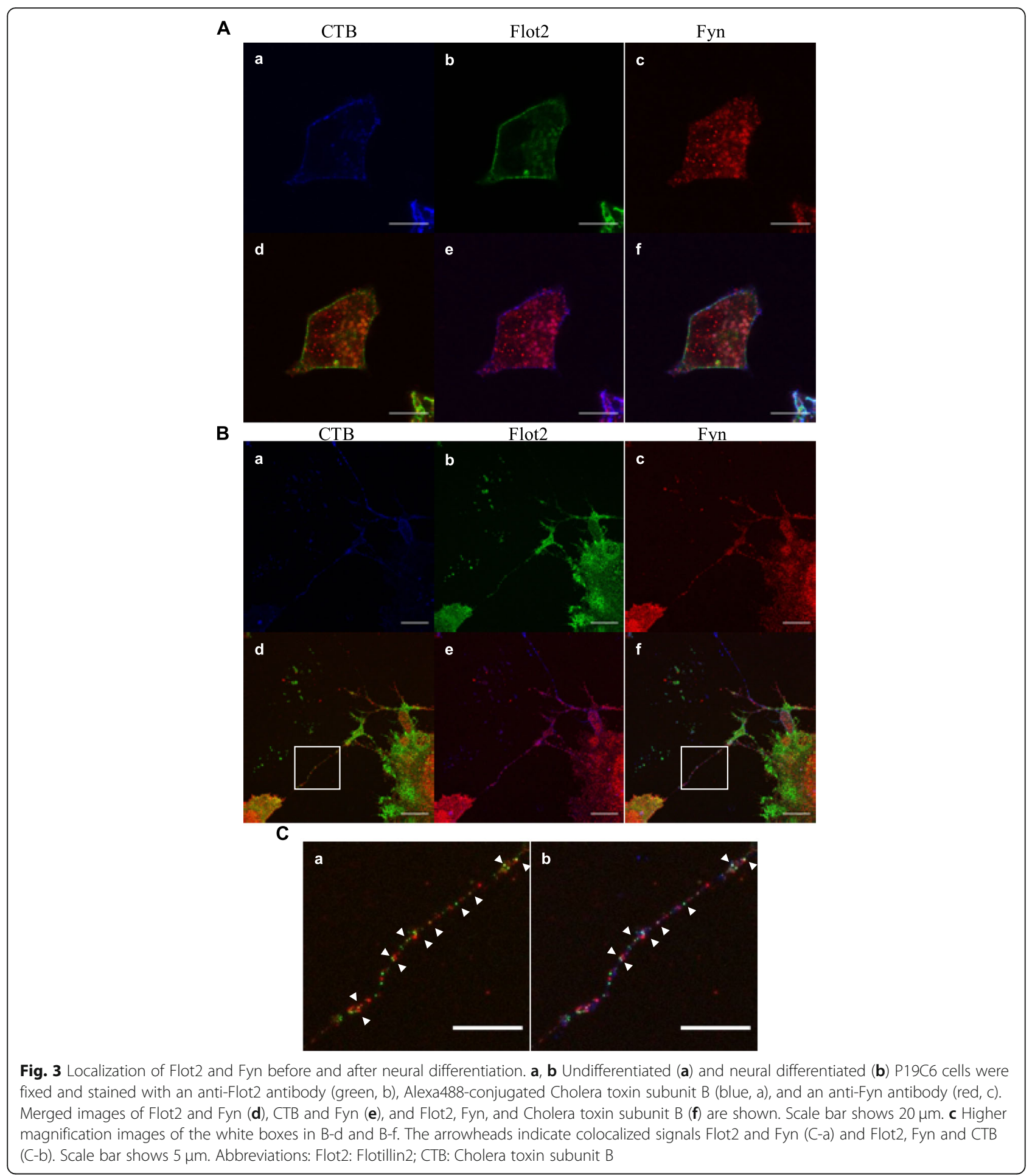

is expressed constitutively in a wide variety of cell types, and NKA activity is related to that of c-Src [53, 54]. NKA interacts with caveolin-1, and the resulting complex forms caveolae-like membrane microdomains that are related to $\mathrm{Ca}^{2+}$ signaling via phosphoinotiside-3 kinase $[55,56]$. In the current study, NKA was localized at the plasma membrane and was not recovered in the
DRM Frs of P19C6 cells. This finding may be explained by the fact that neuronal cells are devoid of caveolin-1 and caveolae [14, 57].

The levels of Flot2 and Fyn increased during neural differentiation of P19C6 cells (Fig. 1c and d). The recovery ratio of DRM-associated Fyn did not change during neural differentiation (Fig. $2 \mathrm{~b}$ and g); however, the 
recovery ratio of inactive Fyn and/or c-Src was decreased in DRM Frs (Fig. 2d and i). Therefore, the level of DRM-associated active Fyn might be increased, but the combined level of DRM-associated phosphorylated Fyn (pY528) and/or phosphorylated c-Src (pY530) might be decreased in Neu. These results suggest that level of the active form of Fyn might be increased in DRM Frs during neural cells [58]. Taken together, these results raise the possibility that Flot2 lipid rafts are associated with Fyn, and that Fyn may phosphorylate Flot2 during neural differentiation of P19C6 cells.

The active form of Fyn binds to membrane-bound $\gamma$ tubulin via phosphorylated $\mathrm{SH} 2$ domains and forms the core of the microtubule organizing center with $\gamma$-tubulin during neural differentiation [35]. This core promotes microtubule nucleation by phosphoinositide 3-kinase [28]. Flot2 phosphorylation causes endocytosis, resulting in cargo formation to deliver the endocytosed materials to growth cone outgrowths $[25,59]$. Moreover, Flot2 interacts with cytoskeletal proteins in lipid rafts [24]. These observations raise the possibility that Flot2-associated lipid rafts may be involved in morphological changes such as cytoskeletal remodeling during neural differentiation. Further studies are needed to elucidate the roles of Flot2- and Fyn-associated lipid rafts in neural differentiation and neurite outgrowth.

\section{Conclusion}

During neural differentiation of P19 cells, Flot2 tend to localize in DRM Frs. Moreover, our data suggested that not only the observed distribution of Fyn but also the amount of activated Fyn in DRM Frs might be increased during neural differentiation. These findings suggested that Flot2 lipid rafts are associated with Fyn. This association might cause the phosphorylation of Flot2 during neural differentiation. Our findings, the association between lipid raft scaffold protein, Flot2, and acylated proteins such as Fyn, c-Src, may be the key concept of development and function of central nervous system.

\section{Methods}

\section{Reagents}

P19C6 cells were obtained from the RIKEN Bioresource Center Cell Bank (Ibaraki, Japan). Alexa405-conjugated goat polyclonal anti-mouse IgG H\&L (No. ab175660; used at a 1:500 dilution) and the rabbit monoclonal antiFyn antibody [EPR5500] (ab125016; WB: 1:1000; IF: 1: $500)$ were purchased from Abcam (Cambridge, UK). The mouse monoclonal anti-Flot2 antibody (No. 610383; WB: 1:4000; immunofluorescence: 1:500) and mouse monoclonal anti-Fyn (pY528)/c-Src (pY530) antibody (No. 612668; WB: 1:2000) were purchased from BD Biosciences (Franklin Lakes, NJ, USA). The rabbit monoclonal anti-Src (36D10) antibody (\#2109; WB: 1:1000; IF: 1:
100) was purchased from Cell Signaling Technology (Danvers, MA, USA). The 2D-Quant kit was purchased from GE Healthcare (Little Chalfont, UK). Horseradish peroxidase (HRP)-conjugated goat polyclonal anti-mouse IgG (No. 330; 1:5000) and HRP-conjugated goat polyclonal anti-rabbit IgG (No. 458; 1:5000) were purchased from MBL (Nagoya, Japan). The Immobilon-P membrane (IPVH00010) and Immobilon Western Chemiluminescent HRP substrate (No. P36599) were purchased from Millipore (Billerica, MA, USA). The mouse monoclonal anti-Oct-3/4 antibody (sc-5279; WB: 1:1000) was purchased from Santa Cruz Biotechnology (Dallas, TX, USA). The mouse monoclonal anti-MAP2 Clone HM-2 antibody (No. M 9942; 1:1000), the Mammalian Cell Lysis Kit, and Cy3-conjugated sheep polyclonal antirabbit IgG (No. C2306; 1:500) were purchased from Sigma-Aldrich (St. Louis, MO, USA). Rabbit polyclonal antibodies raised against human $\alpha$-tubulin (WB: 1:8000) and against human NKA $\alpha 1$ subunit (WB: 1:1000 or IF: 1:100) were produced by Thermo Fisher Scientific (Waltham, MA, USA). Cholera toxin Subunit B (Recombinant), Alexa Fluor 488 conjugate (C22841) was purchased from Thermo Fisher Scientific (Waltham, MA, USA).

\section{Cell culture}

P19C6 mouse embryonic carcinoma cells were grown in high-glucose Dulbecco's Modified Eagle Medium (DMEM; Thermo Fisher Scientific) supplemented with $10 \%$ heat-inactivated fetal bovine serum (FBS; GE Healthcare) and $1 \%$ penicillin-streptomycin (P/S; Gibco, Waltham, MA, USA) at $37^{\circ} \mathrm{C}$ in at atmosphere containing $5 \% \mathrm{CO}_{2}$.

\section{Neuronal differentiation}

P19 cells are able to differentiate into neuronal cells after all-trans-retinoic acid stimulation and embryoid body formation, as described previously [60]. In the present work, we used a modified version of this method. Briefly, cultured cells were washed three times with phosphate-buffered saline (PBS) and then separated by the addition of $0.25 \%$ trypsin containing $1 \mathrm{mM}$ EDTA. The number of cells was counted using standard methods. An aliquot of $1 \times 10^{6}$ cells was cultured in suspension in a $50 \mathrm{~mL}$ conical tube containing $20 \mathrm{~mL}$ of a 1:1 mixture of DMEM and DMEM/ F12 supplemented with $5 \% \mathrm{FBS}, 1 \% \mathrm{P} / \mathrm{S}$, and $1 \mu \mathrm{M}$ all-trans-retinoic acid (Sigma), in a $5 \% \mathrm{CO}_{2}$ incubator at $37^{\circ} \mathrm{C}$. After 5 days, the medium was aspirated, leaving the cells that had formed aggregates in the $50 \mathrm{~mL}$ conical tube. To dissociate the aggregates, the cells were treated with $0.25 \%$ Trypsin and $1 \mathrm{mM}$ EDTA, and triturated with a pipette. DMEM supplemented with $10 \%$ FBS and $1 \% \mathrm{P} / \mathrm{S}$ was then added, and the suspension was centrifuged. The supernatant was discarded 
and cell pellets were resuspended in DMEM supplemented with $10 \% \mathrm{FBS}$ and $1 \% \mathrm{P} / \mathrm{S}$. To ensure separation of any remaining aggregates into single cells, cell suspensions were passed through a $100 \mu \mathrm{m}$ nylon mesh filter (Becton Dickinson, Franklin Lakes, NJ, USA), and the cells were then seeded onto poly-D-lysine-coated dishes at a density of $2.0 \times 10^{5}$ cells $/ \mathrm{cm}^{2}$.

\section{Sucrose density gradient fractionation}

The culture medium was removed from cell cultures and the cells were washed twice with PBS. Subsequently, the cells were resuspended in lysis buffer $(10 \mathrm{mM}$ Tris$\mathrm{HCl}$ (pH 7.4), $1 \mathrm{mM}$ EDTA, $1 \mathrm{mM}$ EGTA, and 1\% (w/v) Triton X-100) supplemented with $1 \mathrm{mM} \mathrm{Na}_{3} \mathrm{VO}_{4}$ and $1 \%$ protease inhibitor cocktail. After the lysates were placed on ice and homogenized with a Dounce homogenizer, the total volume was adjusted to $2 \mathrm{~mL}$ by the addition of lysis buffer. A $2 \mathrm{~mL}$ aliquot of $80 \%$ sucrose was added to the lysate, and the combination was mixed completely and transferred to a high-speed centrifugation tube. The mixture was then overlaid sequentially with $4 \mathrm{~mL}$ of $30 \%$ sucrose and $4 \mathrm{~mL}$ of $5 \%$ sucrose, and the tube was centrifuged at $37,679 \times g$ for $16 \mathrm{~h}$ at $4{ }^{\circ} \mathrm{C}$ in a SW41Ti rotor (Beckman, Brea, CA, USA). Twelve fractions were collected starting from the top of the surface of the centrifuged liquid.

\section{Western blotting}

The cells were suspended in Mammalian Cell Lysis Kit buffer containing $1 \mathrm{mM} \mathrm{Na}_{3} \mathrm{VO}_{4}$ and $1 \%$ protease inhibitor cocktail, and placed on ice for $30 \mathrm{~min}$ to lyse. The protein concentration of the resulting lysate was determined using the 2D-Quant kit. Aliquots of the samples corresponding to $10 \mu \mathrm{g}$ of total protein were separated by $10 \%$ sodium dodecyl sulfate-polyacrylamide gel electrophoresis and transferred to a polyvinylidene fluoride membrane using a semi-dry apparatus. The blots were blocked by incubation for $1 \mathrm{~h}$ at room temperature (RT) in TBS-T (20 mM Tris- $\mathrm{HCl}$ (pH 7.4), $150 \mathrm{mM} \mathrm{NaCl}$, and $0.1 \%$ Tween 20 ) containing $5 \%$ skimmed milk or $3 \%$ bovine serum albumin. Subsequently, the blots were incubated with the primary antibodies overnight at $4{ }^{\circ} \mathrm{C}$. After washing three times with TBS-T, the blots were incubated with the secondary antibodies for $1 \mathrm{~h}$ at RT. After another three rounds of washing with TBS-T, the blots were reacted with Immobilon Western Chemiluminescent HRP substrate, and the signals were detected using a LuminoShot 400Jr instrument (TAKARA Bio, Shiga, Japan). Intensity analysis was performed using ImageJ/Fiji (ver. 2.0) software [61].

\section{Immunostaining}

Cells that were plated on glass-bottom dishes (MatTek, Ashland, MA, USA) were incubated with $10 \mathrm{nM} \mathrm{CTB}$ conjugated to Alexa488 for $30 \mathrm{~min}$ on ice, fixed with $4 \%$ paraformaldehyde (Sigma) for $15 \mathrm{~min}$ at RT, and then permeabilized with PBS containing $0.1 \%$ Triton X-100 for $5 \mathrm{~min}$ at RT. The cells were then washed three times with PBS, blocked with $0.1 \%$ bovine serum albumin in PBS for $1 \mathrm{~h}$ at RT, and incubated for $1 \mathrm{~h}$ at RT with the primary antibodies in the dark. After three washes $(5 \mathrm{~min}$ each) with PBS, the cells were incubated with the secondary antibodies for $1 \mathrm{~h}$ at RT in the dark. After one wash with PBS-T and three washes ( 5 min each) with PBS, the cells were mounted in $75 \%$ glycerol. Images of the stained cells were acquired using a laser-scanning confocal microscope (LSM780, Carl Zeiss, Germany) equipped with a Plan-Apochromat $\times 63$ immersion lens.

\section{Statistical analysis}

Results were derived from experiments performed at least three separate times. The data are expressed as the mean \pm SEM. Statistical analyses of the data were performed using two-tailed, unpaired Student's $t$-tests. Homoscedasticity of the data was assumed (Microsoft Excel, Redmond, WA, USA) and $p<0.05$ was considered statistically significant.

\section{Additional files}

\begin{abstract}
Additional file 1: Figure S1. Gray scale images of the localization of Flot2 and the other molecules before neural differentiation. (A-C) Undifferentiated P19C6 cells were fixed and stained with an anti-Flot2 antibody (b), Alexa488conjugated Cholera toxin subunit B (a), an anti-Na/K ATPase a1 subunit antibody (NKA, A-C), an anti-Fyn antibody (B-C), and an anti-c-SrC antibody (C$\mathrm{C})$, and their merged images are shown (e). In these merged images, the staining presented in a, b, and c is shown in blue, green, and red, respectively. Differential interference contrast images were also obtained (d). Scale bar shows 10 mm. Abbreviations: Flot2: Flotillin2; NKA: Na/K ATPase; CTB: Cholera toxin subunit B; DIC: Differential interference contrast. (PDF 292 kb)
\end{abstract}

Additional file 2: Figure S2. Gray scale images of the localization of Flot2 and the other molecules after neural differentiation. (A-C) Neural differentiated P19C6 cells were fixed and stained with an anti-Flot2 antibody (b), Alexa488-conjugated Cholera toxin subunit B (a), an anti-Na/ K ATPase a1 subunit antibody (NKA, A-C), an anti-Fyn antibody (B-C), and an anti-c-Src antibody (C-c), and their merged images are shown (e). In these merged images, the staining presented in $a, b$, and $c$ is shown in blue, green, and red, respectively. Differential interference contrast images were also obtained (d). Scale bar shows $20 \mu \mathrm{m}$. (D-E) Higher magnification images of the white boxes in A-e and C-e (blue: Cholera toxin subunit B; green: Flot2; red: NKA or c-Src). Scale bar shows $5 \mu \mathrm{m}$. The arrowheads indicate colocalized signals Flot2 and c-Src (E-b and E-c). Abbreviations: Flot2: Flotillin2; NKA: Na/K ATPase; CTB: Cholera toxin subunit B; DIC: Differential interference contrast. (PDF $318 \mathrm{~kb}$ )

\section{Abbreviations}

CTB: Cholera toxin subunit B; DRM: Detergent-resistant membrane; Flot1: Flotillin-1; Flot2: Flotillin-2; Frs: fractions; hMSCs: human multipotent stromal cells; MAP2: microtubule-associated protein 2; Neu: neural differentiated cells; NKA: Na/K ATPase; Oct-3: Octamer transcription factor-3; UD: undifferentiated cells; WB: Western blotting

\section{Acknowledgments}

The authors thank the Center for Biological Resources and Informatics, Tokyo Institute of Technology, for use of the confocal microscope. The authors also thank Mr. Frans Rodenburg for advice regarding statistical analysis. 


\section{Consent to publication}

No applicable.

\section{Authors' contributions}

$\mathrm{KH}$ performed all experiments. The design, study conduct, and financial support for this research were performed by $\mathrm{NH}$. Both authors read and approved the final manuscript.

\section{Funding}

This work was supported in part by Grants-in-Aid from the Tokyo Institute of Technology and from the Ministry of Education, Science, Sports and Culture of Japan for Scientific Research (Nos. C26460551 and 17 K08854).

Availability of data and materials

No applicable.

\section{Ethics approval and consent to participate}

No applicable.

\section{Competing interests}

No applicable.

Received: 14 August 2019 Accepted: 22 August 2019

Published online: 27 August 2019

\section{References}

1. de Juan-Sanz J, Núñez E, Zafra F, Berrocal M, Corbacho I, Ibáñez I, ArribasGonzález E, Marcos D, López-Corcuera B, Mata AM, Aragón C. Presynaptic control of glycine transporter 2 (GlyT2) by physical and functional association with plasma membrane Ca2+-ATPase (PMCA) and Na+-Ca2+ exchanger (NCX). J Biol Chem. 2014;289:34308-24.

2. Encinas M, Tansey MG, Tsui-Pierchala BA, Comella JX, Milbrandt J, Johnson EM. C-Src is required for glial cell line-derived neurotrophic factor (GDNF) family ligand-mediated neuronal survival via a phosphatidylinositol-3 kinase (PI-3K)-dependent pathway. J Neurosci. 2001;21:1464-72.

3. Guillaume E, Comunale F, Do KN, Planchon D, Bodin S, Gauthier-Rouviere C. Flotillin microdomains stabilize cadherins at cell-cell junctions. JCell Sci. 2013;126:5293-304.

4. Haglund K, Ivankovic-Dikic I, Shimokawa N, Kruh GD, Dikic I. Recruitment of Pyk2 and $\mathrm{Cbl}$ to lipid rafts mediates signals important for actin reorganization in growing neurites. J Cell Sci. 2004;117:2557-68.

5. Kotani N, Nakano T, Ida Y, Ito R, Hashizume M, Yamaguchi A, Seo M, Araki T, Hojo Y, Honke K, Murakoshi T. Analysis of lipid raft molecules in the living brain slices. Neurochem Int. 2018;119:140-50.

6. Langhorst MF, Jaeger F, Mueller S, Sven Hartmann L, Luxenhofer G, Stuermer C. Reggies/flotillins regulate cytoskeletal remodeling during neuronal differentiation via CAP/ponsin and rho GTPases. Eur J Cell Biol. 2008:87:921-31.

7. Vetrivel KS, Cheng H, Lin W, Sakurai T, Li T, Nukina N, Wong PC, Xu H, Thinakaran G. Association of $\gamma$-secretase with lipid rafts in post-golgi and endosome membranes. J Biol Chem. 2004;279:44945-54.

8. Schuck S, Honsho M, Ekroos K, Shevchenko A, Simons K. Resistance of cell membranes to different detergents. Proc Natl Acad Sci USA. 2003;100:5795-800.

9. Simons K, lkonen E. Functional rafts in cell membranes. Nature. 1997;387:569-72.

10. Simons K, Sampaio JL. Membrane organization and lipid rafts. Cold Spring Harb Perspect Biol. 2011;3:a004697.

11. Adamiak M, Poniewierska-Baran A, Borkowska S, Schneider G, AbdelbasetIsmail A, Suszynska M, Abdel-Latif A, Kucia M, Ratajczak J, Ratajczak MZ. Evidence that a lipolytic enzyme-hematopoietic-specific phospholipase C$\beta 2$-promotes mobilization of hematopoietic stem cells by decreasing their lipid raft-mediated bone marrow retention and increasing the promobilizing effects of granulocytes. Leukemia. 2016;30:919-28.

12. Costantini F, Barbieri G. The HLA-DR mediated signalling increases the migration and invasion of melanoma cells, the expression and lipid raft recruitment of adhesion receptors, PD-L1 and signal transduction proteins. Cell Signal. 2017;36:189-203.

13. Palacios-Moreno J, Foltz L, Guo A, Stokes MP, Kuehn ED, George L, Comb M, Grimes ML. Neuroblastoma tyrosine kinase signaling networks involve FYN and LYN in endosomes and lipid rafts. PLoS Comput Biol. 2015;11:1-33.

14. Lang DM, Lommel S, Jung M, Ankerhold R, Petrausch B, Laessing U, Wiechers MF, Plattner $\mathrm{H}$, Stuermer $\mathrm{C}$ a O Identification of reggie-1 and reggie-2 as plasmamembrane-associated proteins which cocluster with activated GPIanchored cell adhesion molecules in non-caveolar micropatches in neurons. J Neurobiol. 1998;37:502-23.

15. López D, Kolter R, Lo D. Functional microdomains in bacterial membranes. Genes Dev. 2010;24:1893-1902.

16. Volonté D, Galbiati F, Li S, Nishiyama K, Okamoto T, Lisanti MP. Flotillins/ cavatellins are differentially expressed in cells and tissues and form a hetero-oligomeric complex with caveolins in vivo: characterization and epitope-mapping of a novel flotillin-1 monoclonal antibody probe. J Biol Chem. 1999:274:12702-9.

17. Schulte T, Paschke KA, Laessing U, Lottspeich F, Stuermer CA. Reggie-1 and reggie-2, two cell surface proteins expressed by retinal ganglion cells during axon regeneration. Development. 1997;124:577-87.

18. Banning $A, C R$ a R, Tikkanen $R$. Increased activity of mitogen activated protein kinase pathway in flotillin-2 knockout mouse model. Cell Signal. 2014;26:198-207.

19. Babuke T, Ruonala M, Meister M, Amaddii M, Genzler C, Esposito A, Tikkanen R. Hetero-oligomerization of reggie-1/flotillin-2 and reggie-2/flotillin-1 is required for their endocytosis. Cell Signal. 2009;21:1287-97.

20. Neumann-Giesen C, Falkenbach B, Beicht P, Claasen S, Lüers G, Stuermer $\mathrm{CAO}$, Herzog $\mathrm{V}$, Tikkanen R. Membrane and raft association of reggie-1/ flotillin-2: role of myristoylation, palmitoylation and oligomerization and induction of filopodia by overexpression. Biochem J. 2004;378:509-18.

21. Bitsikas V, Riento K, Howe JD, Barry NP, Nichols BJ. The role of flotillins in regulating a $\beta$ production, investigated using flotillin 1-/-, flotillin 2-/double knockout mice. PLoS One. 2014:9:e85217.

22. Langhorst MF, Solis GP, Hannbeck S, Plattner H, Stuermer CAO. Linking membrane microdomains to the cytoskeleton: regulation of the lateral mobility of reggie-1/ flotillin-2 by interaction with actin. FEBS Lett. 2007;581:4697-703.

23. Neumann-Giesen C, Fernow I, Amaddii M, Tikkanen R. Role of EGF-induced tyrosine phosphorylation of reggie-1/flotillin-2 in cell spreading and signaling to the actin cytoskeleton. J Cell Sci. 2007;120:395-406.

24. Riento K, Frick M, Schafer I, Nichols BJ. Endocytosis of flotillin-1 and flotillin-2 is regulated by Fyn kinase. J Cell Sci. 2009;122:912-8

25. Bodrikov V, Pauschert A, Kochlamazashvili G, Stuermer CAO. Reggie-1 and reggie-2 (flotillins) participate in Rab11a-dependent cargo trafficking, spine synapse formation and LTP-related AMPA receptor (GluA1) surface exposure in mouse hippocampal neurons. Exp Neurol. 2017;289:31-45.

26. Banning A, Babuke T, Kurrle N, Meister M, Ruonala M, Tikkanen R. Flotillins regulate focal adhesions by interacting with a-Actinin and by influencing the activation of focal adhesion kinase. Cells. 2018;7:28.

27. Klein C, Kramer E-M, Cardine A-M, Schraven B, Brandt R, Trotter J. Process outgrowth of oligodendrocytes is promoted by interaction of fyn kinase with the cytoskeletal protein tau. J Neurosci. 2002;22:698-707.

28. Vacaresse N, Møller B, Danielsen EM, Okada M, Sap J. Activation of c-Src and Fyn kinases by protein-tyrosine phosphatase RPTPa is substrate-specific and compatible with lipid raft localization. J Biol Chem. 2008;283:35815-24.

29. Beggs HE, Soriano P, Maness PF. NCAM-dependent neurite outgrowth is inhibited in neurons from Fyn-minus mice. J Cell Biol. 1994;127:825-33.

30. den Hertog J, Pals CEGM, Peppelenbosch MP, Tertoolen LG, de Laat SW, Kruijer W. Receptor protein tyrosine phosphatase alpha activates pp60c-src and is involved in neuronal differentiation. EMBO J. 1993;12:3789-98.

31. Hayashi N, Nakagawa C, Ito Y, Takasaki A, Jinbo Y, Yamakawa Y, Titani K, Hashimoto K, Izumi Y, Matsushima N. Myristoylation-regulated direct interaction between calcium-bound calmodulin and N-terminal region of pp60v-src. J Mol Biol. 2004;338:169-80.

32. Nada S, Yagi T, Takeda H, Tokunaga T, Nakagawa H, Ikawa Y, Okada M, Aizawa S. Constitutive activation of Src family kinases in mouse embryos that lack Csk. Cell. 1993;73:1125-35.

33. Takayama Y, Nada S, Nagai K, Okada M. Role of Csk in neural differentiation of the embryonic carcinoma cell line P19. FEBS Lett. 1997:406:11-6.

34. Xu W, Harrison SC, Eck MJ. Three-dimensional structure of the tyrosine kinase c-Src. Nature. 1997:385:595-602.

35. Kukharskyy V, Sulimenko V, Macůrek L, Sulimenko T, Dráberová E, Dráber P. Complexes of $y$-tubulin with nonreceptor protein tyrosine kinases Src and Fyn in differentiating P19 embryonal carcinoma cells. Exp Cell Res. 2004;298:218-28.

36. Makdissy N, Haddad K, Albacha JDA, Chaker D, Ismail B, Azar A, Oreib G, Ayoub D, Achkar I, Quilliot D, Fajloun Z. Essential role of ATP6AP2 enrichment in caveolae/lipid raft microdomains for the induction of neuronal differentiation of stem cells. Stem Cell Res Ther. 2018;9:1-24.

37. Bain G, Ray W, Yao M, Gottlieb D. From embryonal carcinoma cells to neurons: the P19 pathway. BioEssays. 1994;16:343-8. 
38. Tanaka Y, Kawahata K, Nakata T, Hirokawa N. Chronological expression of microtubule-associated proteins (MAPs) in EC cell P19 after neuronal induction by retinoic acid. Brain Res. 1992;596:269-78.

39. Schaeuble K, Hauser MA, Singer E, Groettrup M, Legler DF. Cross-talk between TCR and CCR7 signaling sets a temporal threshold for enhanced T lymphocyte migration. J Immunol. 2011;187:5645-52.

40. Cramer ML, Xu R, Martin T. Soluble Heparin Epidermal Growth Factor-Like Growth Factor Is a Regulator of GALGT2 Expression and GALGT2-Dependent Muscle and Neuromuscular Phenotypes. Mol Cell Biol. 2019;39:e0140-19.

41. Grossman H, Chuderland D, Ninio-Many L, Hasky N, Kaplan-Kraicer R, Shalgi R. A novel regulatory pathway in granulosa cells, the $\mathrm{LH} /$ human chorionic gonadotropin-microRNA-125a-3p-Fyn pathway, is required for ovulation. FASEB J. 2015;29:3206-16.

42. Lingwood D, Harauz G, Ballantyne JS. Regulation of fish gill Na+-K+-ATPase by selective sulfatide-enriched raft partitioning during seawater adaptation. J Biol Chem. 2005;280:36545-50.

43. Núñez E, Alonso-Torres P, Fornés A, Aragón C, López-Corcuera B. The neuronal glycine transporter GLYT2 associates with membrane rafts: functional modulation by lipid environment. J Neurochem. 2008;105:2080-90.

44. Watkins J, Basu S, Bogenhagen DF. A quantitative proteomic analysis of mitochondrial participation in p19 cell neuronal differentiation. J Proteome Res. 2008:7:328-38.

45. Ilangumaran S, Hoessli DC. Effects of cholesterol depletion by cyclodextrin on the sphingolipid microdomains of the plasma membrane. Biochem J. 1998;335:433-40.

46. Rajendran L, Beckmann J, Magenau A, Boneberg EM, Gaus K, Viola A, Giebel $B$, Illges $H$. Flotillins are involved in the polarization of primitive and mature hematopoietic cells. PLoS One. 2009:4.

47. Popova D, Karlsson J, Jacobsson SOP. Comparison of neurons derived from mouse P19, rat PC12 and human SH-SY5Y cells in the assessment of chemicaland toxin-induced neurotoxicity. BMC Pharmacol Toxicol. 2017;18:1-11.

48. Greene LA, Tischler AS. Establishment of a noradrenergic clonal line of rat adrenal pheochromocytoma cells which respond to nerve growth factor. Proc Natl Acad Sci. 1976;73:2424-8.

49. McBurney MW. P19 embryonal carcinoma cells. Int J Dev Biol. 1993;37:135-40.

50. Pittenger MF. Multilineage potential of adult human mesenchymal stem cells. Science. 1999;284:143-7.

51. Edwards MKS, McBurney MW. The concentration of retinoic acid determines the differentiated cell types formed by a teratocarcinoma cell line. Dev Biol. 1983;98:187-91.

52. Pietrini G, Matteoli M, Banker G, Caplan MJ. Isoforms of the Na,K-ATPase are present in both axons and dendrites of hippocampal neurons in culture. Proc Natl Acad Sci U S A. 1992;89:8414-8.

53. Li Z, Xie Z. The Na/K-ATPase/Src complex and cardiotonic steroid-activated protein kinase cascades. Pflugers Arch Eur J Physiol. 2009;457:635-44.

54. Ye Q, Lai F, Banerjee M, Duan Q, Li Z, Si S, Xie Z. Expression of mutant a1 $\mathrm{Na/K}$-ATpase defective in conformational transition attenuates src-mediated signal transduction. J Biol Chem. 2013;288:5803-14.

55. Tian J, Xie Z. The Na-K-ATPase and calcium-signaling microdomains. Physiology. 2008;23:205-211.

56. Cai T, Wang H, Chen Y, Liu L, Gunning WT, Quintas LEM, Xie Z. Regulation of caveolin-1 membrane trafficking by the Na/K-ATPase. J Cell Biol. 2008;182:1153-69.

57. Simons K, Toomre D. Lipid rafts and signal transduction. NatRevMolCell Biol. 2000;1:31-9.

58. Stuermer CA, Lang DM, Kirsch F, Wiechers M, Deininger SO, Plattner $\mathrm{H}$. Glycosylphosphatidyl inositol-anchored proteins and fyn kinase assemble in noncaveolar plasma membrane microdomains defined by reggie-1 and -2 . Mol Biol Cell. 2001;12:3031-45.

59. Bodrikov V, Solis GP, Stuermer CAO. Prion protein promotes growth cone development through Reggie/Flotillin-dependent $\mathrm{N}$-cadherin trafficking. J Neurosci. 2011;31:18013-25.

60. MacPherson P. P19 embryonal carcinoma cells: a source of cultured neurons amenable to genetic manipulation. Methods. 1995.

61. Schindelin J, Arganda-Carreras I, Frise E, Kaynig V, Longair M, Pietzsch T, Preibisch S, Rueden C, Saalfeld S, Schmid B, Tinevez JY, White DJ, Hartenstein V, Eliceiri K, Tomancak P, Cardona A. Fiji: an open-source platform for biological-image analysis. Nat Methods. 2012;9:676-82.

\section{Publisher's Note}

Springer Nature remains neutral with regard to jurisdictional claims in published maps and institutional affiliations.

\section{Ready to submit your research? Choose BMC and benefit from}

- fast, convenient online submission

- thorough peer review by experienced researchers in your field

- rapid publication on acceptance

- support for research data, including large and complex data types

- gold Open Access which fosters wider collaboration and increased citations

- maximum visibility for your research: over $100 \mathrm{M}$ website views per year

At BMC, research is always in progress.

Learn more biomedcentral.com/submissions 